\title{
Crisis entre MEDIOS y POLÍTICA
}

Por Philip Schlesinger, director del Stirling Media Research Institute, Universidad de Stirling, Escocia

Las relaciones entre el periodismo y el mundo de la política han sido asunto de debate en el Reino Unido, donde los propios periodistas, al igual que las sociedades académicas y universidades, son quienes cuestionan y discuten el tema.

Freesheet: publicación de distribución gratuita. Este tipo de publicación está creando el hábito, especialmente entre los jóvenes, de pensar en e diario como un producto por el cual no hay que pagar, y está comenzando a incidir en la circulación
Las interrogantes surgieron del propio periodismo, al menos dentro del segmento de periodistas del ala liberal, así como de las organizaciones del servicio de difusión pública, y de figuras que tienen una posición notoria en el periodismo británico como J ohn Lloyd, del Financial Times Magazine, Andrew Marr y J eremy Pasman, de la BBC, Alan Rusbridger, de The Guardian, of on Snow, deChannel 4 News.

Al mismo tiempo que los periodistas planteaban sus inquietudes sin llegar a un diagnóstico idéntico, las sociedades académicas y universidades del Reino Unido también analizaban la problemática. Por ejemplo, la Royal Society of Arts y la revista The Economist, auspiciaron en Londres un debate acerca del poder de los periodistas; y el mismo año, 2004, The Royal Society of Edinburgh se cuestionó acerca de la confianza del público en los medios de comunicación. Por su parte, el diario The Guardian dedicó en enero de 2005 un suplemento completo a dar cuenta de las críticas que algunas figuras de la vida pública en el Reino Unido han realizado al periodismo. Las universidades también han generado espacios para la discusión de estos temas. Por ejemplo, en Stirling University, se llevaron a cabo una serie de conferencias brindadas por destacados periodistas que reflexionaron sobre la práctica periodística en tiempos de cambios tecnológicos y de mercado, así como en tiempos de guerra y paz.

Estos cuestionamientos surgen en el particular entorno mediático del Reino Unido, donde el número de medios y el alcance territorial nacional que tienela prensa es excepcional si se compara con otros países, y donde el público es todavía un importante lector y comprador de diarios, a pesar de la incidencia de las publicaciones de distribución gratuita. ${ }^{1}$ Un paisaje mediático en el cual la propiedad de los medios de 


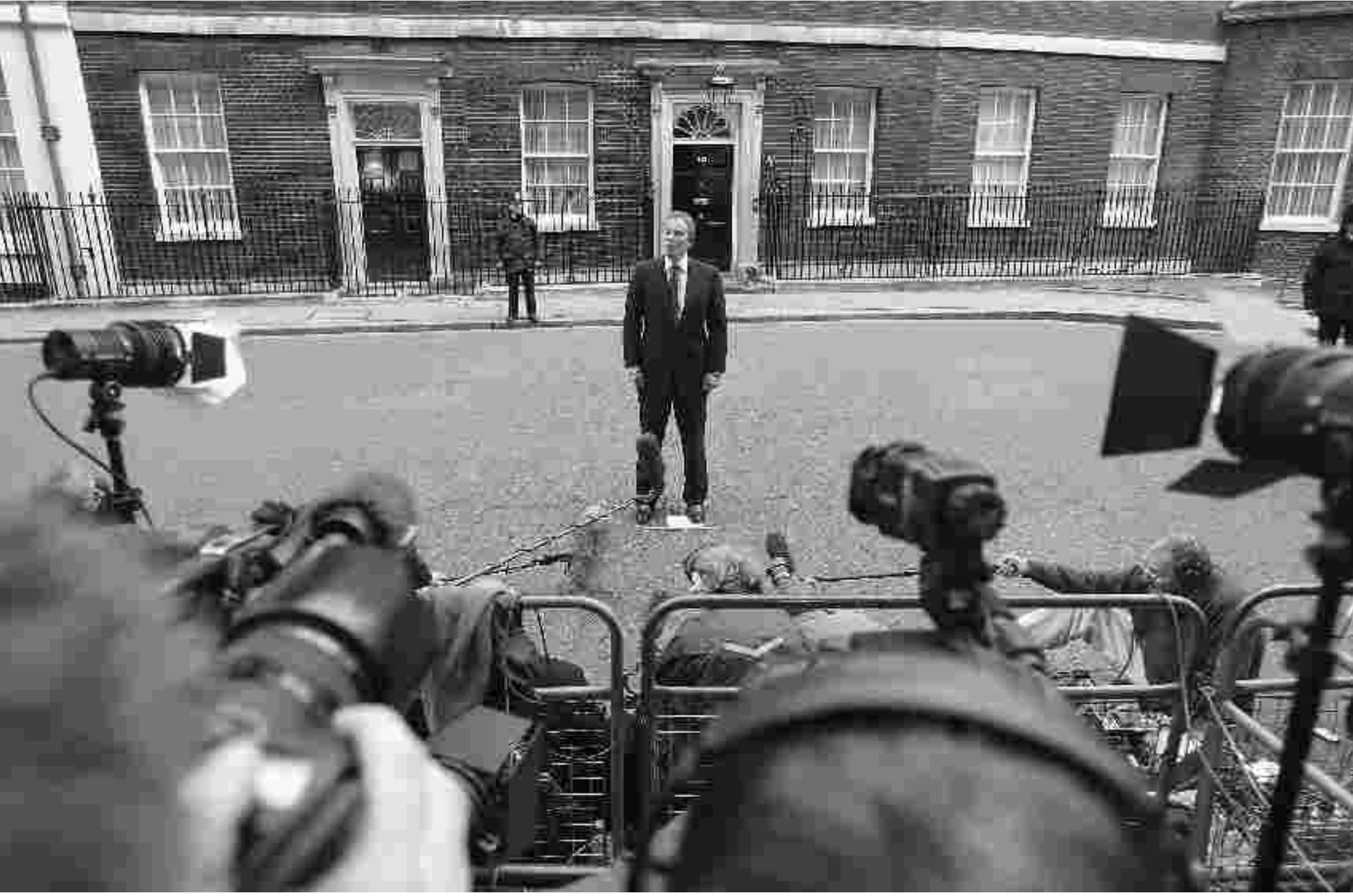

comunicación está altamente concentrada en torno a grupos como News International (The Times, The Sun, y Sky TV) Barclay Brothers, (The Telegraph Group); Daily Mail \& General Trust (M ail y M etro); Northern \& Shell (Express y The Star); Trinity Mirror (Mirrors, The Record); Independent News \& Media (Independent) y Guardian Media Group (The Guardian, The Observer). Todos estos grupos tienen sede en Londres, que es la capital de los medios de comunicación, así como la capital política, financiera, comercial, cultural y turística del Reino Unido.

Que estos cuestionamientos, acerca de las relaciones entre los medios de comunicación y el mundo de la política, hayan surgido dentro del periodismo, resulta coherente con la tradición de autorregulación que tiene la prensa británica, cuyo ejercicio está a cargo de la Comisión de Quejas a la Prensa. ${ }^{2}$ Los periodistas del Reino Unido se han resistido con firmeza a cualquier forma de regulación estatutaria, y esta discusión promovida por los periodistas críticos del periodismo en busca de mejores maneras de autorregularse, está de acuerdo con ese antiguo deseo de mantener al Estado fuera de la determinación de las normas. Sin embargo, cabe preguntar si alcanzan las buenas intenciones, 0 se necesitan regulaciones estatutarias como en el caso de la radiodifusión británica.

Las dudas acerca de la observancia del código de conducta son innegables. El columnista de The Guardian, Roy Greenslade, escribió acerca de los casos más importantes de intrusión a la privacidad que las víctimas temieron hacer públicas por miedo a que la difusión empeorara las cosas. Por ejemplo, Greenslade escribió a propósito de una antigua personalidad de televisión que descubrió que los diarios habían utilizado un subterfugio para acceder a su teléfono y a su historia médica. El mercado de los diarios y
$2::$ Complaints Commission (PCC).

Foto AFP PHOTO / HO J eff Overs 
$3::$

N. del T. Spin: hacer girar, darle la vuelta. En deportes: torcer 0 darle efecto a la dirección de la pelota. Por analogía: manejar la noticia dándole un "efecto". El spin doctor es la persona que realiza esa tarea.

Philip Schlesinger::

(1948)

Licenciado en

Filosofía, Política y

Economía en la

Universidad de Oxford,

y Doctorado en

Sociología en la

Universidad de Londres

(LSE). Actualmente es

director del Media

Research Institute de

la Universidad de

Stirling y miembro del

Comité Consultor

Escocés de Ofcom

(Office of

Communications). periódicos es extremadamente competitivo y busca agresivamente lectores e ingresos por publicidad, lo que determina la manera en que se compite por las historias y, quizá, la ética que se emplea en algunas secciones. El periodismo de la chequera, las invasiones a la privacidad, y el incitar a "darse un beso y contar su historia" está a la orden del día, y se relaciona con el extraordinario crecimiento del culto a las celebridades, por el cual la vida de las estrellas ya sean actores, deportistas, músicos pop y rock se ha convertido en el centro de la agenda popular.

Este culto a las celebridades se ha filtrado en los medios, donde los comentadores y presentadores pueden tener también la condición de estrella, lo que aunque no los hace inmunes a la crítica les da una gran prominencia.

Asimismo, se ha filtrado en la manera de entender la política, y sin duda se ha convertido en una forma de comprender la monarquía. Tanto los políticos como la corona tienen que jugar respetando las duras reglas de las estrategias promocionales en el mercado de los medios de comunicación. Tienen que venderse a sí mismos para adquirir credibilidad y al mismo tiempo aparentar que no lo están haciendo. La fallecida Princesa Diana era, en el mejor de los casos, un excelente exponente de este juego con los medios. Pero también fue una víctima de los medios, lo que para muchos parece ser una parte inevitable de la exposición al público.

El culto a las celebridades en sociedades como la del Reino Unido es una manera de explorar el cambio en las relaciones entre las esferas pública y privada. Es un excelente índice para observar lo que la sociedad piensa que debería estar en el dominio público. Es decir, las cosas que podrían producir vergüenza y humillación están siendo renegociadas. Y el principal lugar en el que esto se está llevando a cabo es en los diversos tipos de reality shows de la televisión, donde los participantes exponen sus vidas privadas. Gran hermano, Cambio de esposas, Ídolo pop, El club de los gordos, etcétera, etcétera, atraen el voyeurismo del público y cambian los límites. A parece gente supuestamente común y corriente a desnudar sus almas, y a menudo sus cuerpos. La sexualidad, la masa corporal, las relaciones íntimas, todo queda expuesto a la mirada del público con un impacto que todavía no comprendemos plenamente.

Una de las consecuencias de este movimiento bastante amplio en la economía moral es que el manejo de la imagen cobra cada vez más importancia. Pero no sólo es una consecuencia, sino también una causa. Recurrir a las relaciones públicas en su sentido más amplio no es nada nuevo, pero con la aparición del culto a las celebridades se ha hecho cada vez más frecuente. De hecho, ha estado en el corazón del gobierno británico durante las últimas tres décadas, y lo que se entiende cada vez más como "la crisis del periodismo" está íntimamente relacionado con la aparición del "spindoctor" ${ }^{3}$ en el gobierno.

El aumento de ese tipo de manejo de los medios (spin) ha sido particularmente notable desde fines de los setenta y principios de los ochenta, fundamentalmente con el advenimiento al poder de Margaret Thatcher. Su secretario de prensa, Bernard Ingham, ejerció una manipulación efectiva de los medios, y aparentemente era un maestro de las filtraciones relacionadas con los rivales de Thatcher.

Otro aspecto importante fue el ingreso a la comunicación política de expertos de marketing y relaciones públicas, como Tim Bell, Gordon Reece y los hermanos Saatchi. La estilización de la política se convirtió en norma.

Esto puede verse como parte de la construcción de una 'cultura promocional' más amplia. Cuando Tony Blair, actual Primer Ministro, asumió como líder del partido Laborista en 1994, trajo consigo una red de asesores de comunicaciones dirigidos por Peter Mandelson y Alastair Campbell. Este último fue una figura de influencia clave en el manejo de las noticias en el 


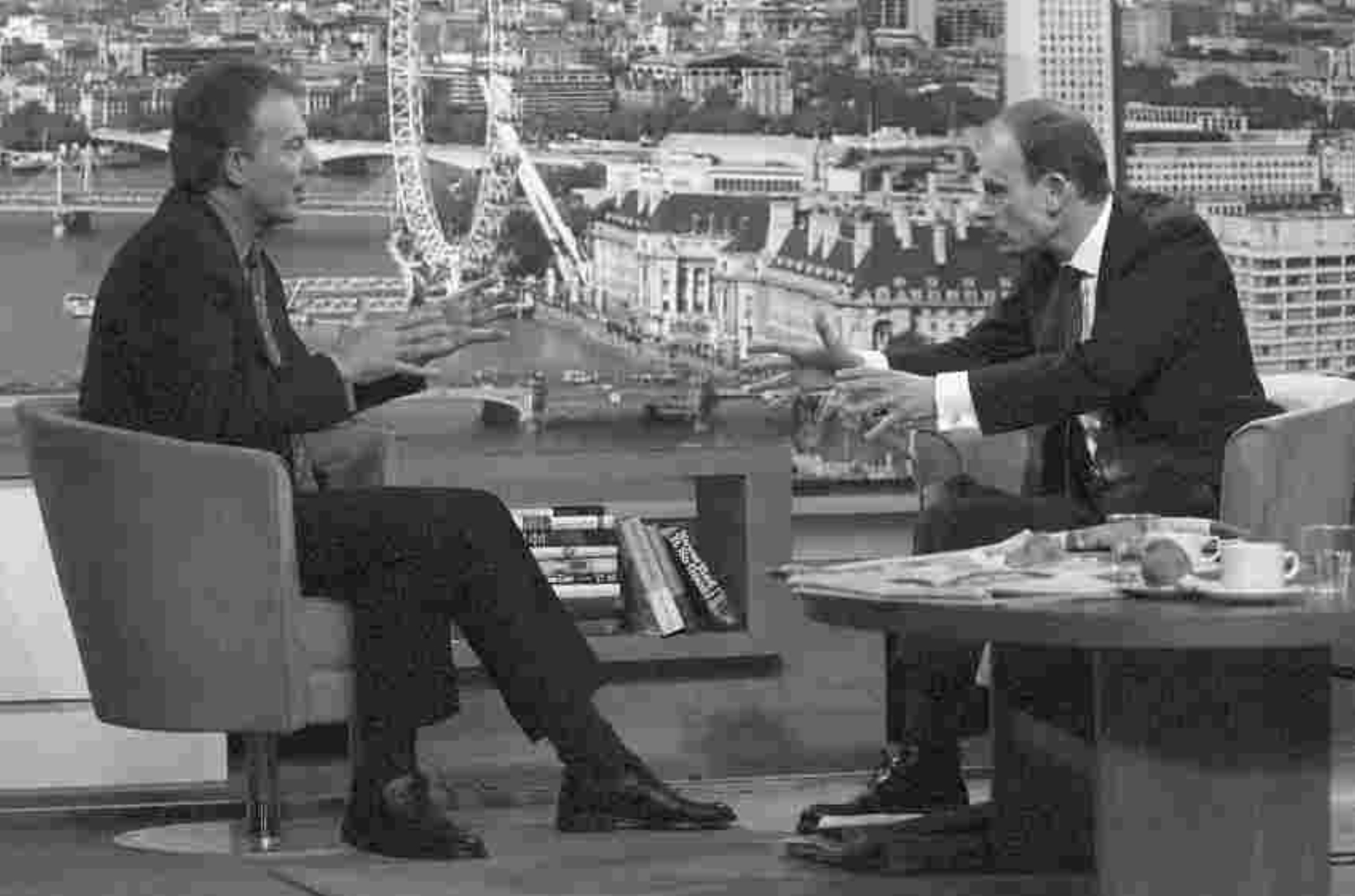

gobierno de 1997 a 2003. Blair también recurrió al mundo del marketing, la publicidad y las relaciones públicas con Philip Gould como experto en encuestas, o por ejemplo, cuando tuvo a Barbara Follett como asesora de imagen.

El spin o "darle la vuelta, imprimir efecto" llegó a caracterizar la nueva política del Laborismo y, especial mente, las malas relaciones entre los asesores de comunicaciones de Blair, Mandelson y Campbell, y los medios: en vez de manipular a los medios, el spin doctor se convirtió cada vez más en la historia en sí.

El spin funcionó durante un tiempo, y finalmente produjo una reacción hostil de parte de los periodistas que pensaban (con bastante razón) que estaban siendo manipulados. La respuesta de los medios fue exponer la manipulación. Se hicieron trabajos periodísticos para desenmascarar el manejo de los medios, mostrando cómo se llevaba a cabo. Entre estos trabajos se encuentra la serie de libros de Nicholas Jones, quien durante mucho tiempo fue el corresponsal político de la BBC, y una bête noire de Alistair Campbell. Esta mirada, puesta en el proceso de spin, alimentó el cinismo público sobre las motivaciones de los políticos. Así, cuando llegó la campaña para las elecciones generales en el Reino Unido en 2005, las cuestiones vinculadas al manejo de imágenes, la filtración selectiva de las noticias y el uso agresivo de información errónea, fueron esenciales, como nunca antes, para la agenda política.

Es a esta situación que al gunos de los exponentes más atentos de la profesión han denominado como la "crisis" en el periodismo, que también es una crisis en el sistema político, y parte de una crisis más amplia de confianza que ya ha sido identificada por la filósofa Onora O'Neill.
Foto AFP PHOTO / HO Leon Neal 
Alan Rusbridger, editor de The Guardian, en una conferencia en Stirling University, identificó dos sistemas de creencias que compiten, para explicar el nexo entre la política y el periodismo. En el sistema de creencia de los periodistas se critica la influencia de los spin doctors, el manejo de la agenda de noticias y la agenda política, la negativa a responder preguntas, el uso de filtraciones extraoficiales, la marginación del parlamento y el uso de los estudios de las emisoras, así como la centralización del poder en la oficina del Primer Ministro. Por su parte, en el sistema de creencias de los políticos se critica la trivialización de los medios y la concentración de la atención en las personalidades $y / 0$ en el conflicto, el habitual descreimiento de las justificaciones de sus acciones para defensa del "interés público" y los ataques a su vida privada. Rusbridger argumenta que se deben dejar de lado los conflictos, y que tanto los políticos como los medios deben dar pasos de acercamiento recíprocos.

A sí como Rusbridger es equitativo en su diagnóstico y ve culpa en ambos lados, J ohn Lloyd, del Financial Times Magazine, no lo es. Lloyd habla de la "cultura de cinismo" del periodismo: un cierto tipo de periodismo se ha vuelto políticamente peligroso para la democracia. Según Lloyd, ese periodismo comparte el negativismo hacia quienes ostentan el poder público. Para él, los problemas residen particularmente en la prensa, a la que considera falaz, tendenciosa y simplista en su tratamiento de los asuntos. Pero también cree que la BBC y la difusión, en términos más generales, han agotado y abandonado las normas de un buen periodismo, inquisidor y riguroso. Como contraposición, establece un objetivo normativo, que es el de "darle a la sociedad relatos veraces de sus propios mecanismos, dilemas y desafíos". Para él, el periodismo británico está en un estado de falla cívica crónica. A diferencia de los comentadores periodísticos, argumenta que los medios se han convertido en un peligro para la democracia, especialmente porque el acceso al público a través de los medios está dado sobre "términos cada vez más duros". Según Lloyd, en las luchas de poder entre los medios y la política, la política ahora está del lado perdedor.

Si bien la importancia de la política mediatizada ha crecido en los últimos veinte años contrariamente a lo que afirma Lloyd esto no le haya quitado poder a los políticos, sino que ha cambiado la naturaleza de su juego y los ha sometido a políticas de exposición. Se podría decir que la creciente interconexión de los medios y la política ha llevado a una crisis entre los medios decomunicación y el mundo de la política.

Por otro lado, esta crisis también impacta en el público, entre el cual se observa una pérdida de respeto por la clase política y falta de credibilidad en la prensa. La pérdida de respeto por la clase política, demostrada por encuestas repetidas, es lo que deplora J ohn Lloyd y de lo que responsabiliza a los medios de comunicación.

Es indudable que también hay acciones y actitudes de los políticos que contribuyen a esta pérdida de respeto, como no cumplir con las promesas electorales, verse involucrados en diferentes formas de corrupción y no responder a las preguntas sobre política de una manera honesta generando así esta reacción del público. Este último punto de vista ha sido abordado en particular por periodistas que no están de acuerdo con J ohn Lloyd, tales como J eremy Paxman de la BBC y J onathan Dimbleby de ITV. El 70 por ciento de los espectadores no está interesado en la cobertura televisiva de las el ecciones: Ios que miraban los resultados electorales por tel evisión cayeron de 12 millones en 1992 a cinco millones en 2001. En la elección general de 2001 el porcentaje de votantes fue 59 por ciento, el más bajo desde 1918.

Por otro lado, los programas de noticias tienen un público cada vez más joven entre los menores de 45 años. J on Snow, del Channel 4 News, opina que lo que ha producido la gran desconexión no es tanto una 
falta de interés en la política sino una alienación por el cariz que han tomado ahora las políticas institucionales del gobierno. En las elecciones generales de 2005, el voto porcentual se elevó levemente, a 61 por ciento. La BBC informó que la audiencia promedio para la cobertura de la elección fue idéntica a la de 2001.

En cuanto a la falta de credibilidad en el periodismo, si bien hay muchas excepciones a esto, particularmente las noticias tel evisivas sólo un cuarto del público británico dice que confía en los diarios (comparado con 50 por ciento en la Unión Europea) y hubo una caída del 25 por ciento en la circulación de los diarios en losúltimos cuarenta años.

Uno de los asuntos que provocó más debate en los últimos tiempos en el Reino Unido es la cobertura de la invasión a Irak. La pregunta clave ha sido cómo cubrir periodísticamente esta guerra cuando casi la mitad de la gente estaba en contra, y no dividida puramente sobre una base partidaria.

La controversia más sonada ha sido protagonizada por la BBC luego de la famosa audición radial de Andrew Gilligan cuando informó, en la mañana del 29 de mayo de 2003, que al dossier del gobierno sobre la inteligencia de Irak se le había agregado información exagerando la capacidad armamentística de Irak para "hacerlo más atractivo". El conflicto surgió en torno a la implicación de que el gobierno estaba engañando al público para crear un clima de intervención y fue a la oficina del primer ministro y su jefe de comunicaciones, Campbell a quienes se señaló con el dedo. Luego, hubo una larga cadena de sucesos que incluyó meses de peleas entre la BBC y Downing Street, la "salida" y muerte de quien fuera la fuente de la historia, experto en armas, el doctor David Kelly, y luego la investigación de Lord Hutton sobre su suicidio. El informe de Lord Hutton, simplificando, halló al gobierno inocente y a la BBC culpable. Seguidamente aparecieron las renuncias de las figuras más altas de la BBC: quedaron afuera el presidente y el director general.

A continuación, vino la presión por reformar el sistema de gobierno de la BBC, aunque no es un simple tema técnico, de rectificar una falla en el sistema. También hay que ver esta presión en el contexto de una oposición contra el poder cultural y político de la BBC desde algunos sectores con intereses creados, en un momento de transformaciones muy importantes en la regulación de los medios de comunicación y en el mercado de la radio y teledifusión. Pero hubo un problema con la victoria del gobierno post Hutton en 2004, porque en lo que John Lloyd ha denominado "el mercado para la confianza de la gente", fue la BBC la que ganó, más que el gobierno. Con una relación de dos a uno, el público dijo confiar más en la BBC que en el gobierno. Más aún, como revelara más tarde Alan Rusbridger, en el corazón del establishment había quienes opinaban que donde el Parlamento había fallado, la prensa luego del informe de Gilligan había logrado poner de manifiesto un uso cuestionable de la inteligencia del gobierno, y fallas en el proceso.

En las elecciones generales de mayo de 2005 el número de habilitados para votar, y que efectivamente lo hizo, fue levemente superior a 2001. Durante la campaña, uno de los asuntos que salió constantemente a la superficie fue la desconfianza generalizada del público hacia la política, y para algunos sectores, un problema especial fue la conducta del primer ministro Tony Blair en la batalla informativa sobre la guerra de Irak. Él mismo reconoció el daño que este tema le hizo a su credibilidad personal.

Sin embargo, la crisis entre los medios de comunicación y la política es mucho más profunda que esta única cuestión (de la guerra en Irak) que es la que se ha convertido en el Reino Unido, en el pararrayos simbólico de algo mucho más amplio.:H
Conferencia dictada por el Profesor Philip Schlesinger en el marco de una gira regional organizada en julio 2005 por la Embajada Británica en Montevideo. 